\title{
Local cerebral glucose utilisation in chronic alcoholics: a positron tomographic study
}

\author{
YVES SAMSON,* JEAN-CLAUDE BARON, ${ }^{\dagger} \dagger$ ANDRÉ FELINE, \\ JACQUES BORIES,§ CHRISTIAN CROUZEL* \\ From Service Hospitalier Frédéric Joliot CEA, Département de Biologie (Orsay), ${ }^{*}$ Clinique des Maladies du \\ Système Nerveux, La Salpétrière, † Service de Psychiatrie, Hôpital Kremlin Bicêtre, $\ddagger$ Service de \\ Neuroradiologie, La Salpétrière,§ Paris, France
}

SUMMARY Using positron tomography, a study of regional cerebral glucose utilisation was performed prospectively in a highly selected group of six neurologically unaffected primary chronic alcoholics. In this group, neuropsychological, behavioural and CT scan anomalies were comparable with those previously reported in more extensive studies. With respect to age-matched control values, cerebral metabolic rate was not significantly modified in the selected cortical, subcortical and cerebellar regions of interest. However, the metabolic regional distribution index, which reflects the distribution pattern of glucose utilisation, was selectively and significantly decreased in the mediofrontal area, pointing to a limbic metabolic dysfunction apparently linked to chronic alcoholism.

Even in apparently neurologically unaffected subjects, chronic alcohol abuse may be associated with some degree of cerebral dysfunction. Neuropsychological studies have demonstrated impairment of several motor, spatio-visual and memory functions, despite approximately preserved IQ. ${ }^{1-5}$ Changes in cerebral blood flow have been also reported. ${ }^{6-8}$ Although pathological studies reported only equivocal cortical alterations in chronic alcoholics, 5910 the occurrence of widened cortical sulci (cerebral atrophy) has been demonstrated in vivo by numerous CT scan studies. ${ }^{11-16}$ However, the precise mechanism of the reported morphological and neuropsychological changes, and the interrelationships among the two, remain largely unknown. ${ }^{2}$ Experimentally, alterations of neuronal membranes, ${ }^{17}$ alteration of dopaminergic and gabaergic systems, ${ }^{18-21}$ as well as selective vulnerability of hippocampal neurons, ${ }^{22} 23$ have been reported, strengthening the hypothesis that alcohol alters neuron function and even perhaps structure. The present study was an attempt to determine by means of positron tomography (PET) if abnormal cerebral glucose utilisation (CMRGlu) could be found in a clinically homogeneous sample of highly selected neurologically unaffected chronic alcoholics.

Address for reprint requests: Yves Samson, Service Hospitalier Frédéric Joliot Hôpital d'Orsay, 91406 Orsay, France.

Received 13 August 1985 and in revised form 9 December 1985. Accepted 15 December 1985

\section{Methods}

Six subjects admitted to the psychiatric department of a general hospital were prospectively selected on the following criteria: 30-60 years of age, chronic dependence on alcohol (DSM III), present hospital admission directly related to alcoholism, right handedness, provision of informed consent. Criteria of exclusion were: preexistent psychiatric, neurological or severe physical disease (including alcoholrelated encephalopathy), head trauma with loss of consciousness, seizures, clinically obvious hepatic cirrhosis or insufficiency and drug abuse.

Neurological and psychiatric clinical examination, including a standardised questionnaire about drinking history and sociobehavioural alterations was performed for each subject, as well as EEG, CT and routine biological laboratory tests. Neuropsychological testing was also performed, including performance and verbal IQ determination, cognitive tasks (Wisconsin Cards Sorting test), Rey's figure copy and delayed reproduction, Weschler memory test or battery $144,{ }^{24}$ Luria series.

Using the ${ }^{18} \mathrm{~F}$-fluoro-2-deoxy-D-Glucose $\left({ }^{18} \mathrm{FDG}\right)$ method $^{26}$ PET studies were carried out on an ECAT II, between the end of the first week and the end of the first month of the hospital admission with apparent abstinence. Three adjacent brain levels were scanned consecutively (respectively 15, 35, $55 \mathrm{~mm}$ above and parallel to the orbitomeatal line) on subjects at rest, eyes closed, ears unplugged and free from any medication for at least 24 hours, according to our usual protocol. ${ }^{25}$ Briefly, all images were corrected for attenuation using $\mathrm{Ge}^{68}-\mathrm{Ga}^{68}$ transmission scans; ${ }^{18} \mathrm{FDG}$ radioactivity blood curve was obtained from crosscalibrated plasma counting of serial arterial blood samples, 
Table Regional cerebral metabolic rate of glucose

\begin{tabular}{|c|c|c|c|c|c|c|c|c|c|c|c|c|c|c|}
\hline & \multirow[t]{2}{*}{$M F I I$} & \multirow[t]{2}{*}{$M O I I$} & \multicolumn{2}{|l|}{$L F I I$} & \multicolumn{2}{|l|}{$T I I$} & \multicolumn{2}{|l|}{$T O$} & \multicolumn{2}{|l|}{$O L I I$} & \multicolumn{2}{|l|}{$T h$} & \multicolumn{2}{|l|}{$C d$} \\
\hline & & & $L$ & $R$ & $L$ & $R$ & $L$ & $R$ & $L$ & $R$ & $L$ & $R$ & $L$ & $R$ \\
\hline $\begin{array}{c}\text { Alcoholics } \\
n=6 \\
\text { Controls } \\
n=6 \\
\end{array}$ & $\begin{array}{l}6.16 \pm \\
1.23 \\
6.96 \pm \\
1.32 \\
\end{array}$ & $\begin{array}{l}7 \cdot 36 \pm \\
1.35 \\
7 \cdot 77 \pm \\
1.35\end{array}$ & $\begin{array}{l}5.93 \pm \\
1.16 \\
6.22 \pm \\
1.05\end{array}$ & $\begin{array}{l}5.89 \pm \\
1.17 \\
6.51 \pm \\
1.14\end{array}$ & $\begin{array}{l}6.32 \pm \\
1.14 \\
6.63 \pm \\
1.03\end{array}$ & $\begin{array}{l}6.44 \pm \\
1.24 \\
6.88 \pm \\
1.04\end{array}$ & $\begin{array}{l}5.80 \pm \\
1.06 \\
6.4 \pm \\
1.08\end{array}$ & $\begin{array}{l}5.89 \pm \\
0.96 \\
6.25 \pm \\
1.06\end{array}$ & $\begin{array}{l}7.09 \pm \\
1.34 \\
7.33 \pm \\
1.03\end{array}$ & $\begin{array}{l}6 \cdot 95 \pm \\
1.21 \\
7 \cdot 52 \pm \\
1 \cdot 29\end{array}$ & $\begin{array}{l}5.41 \pm \\
1.29 \\
5 \cdot 32 \pm \\
1.12\end{array}$ & $\begin{array}{l}5.41 \pm \\
1.36 \\
5.24 \pm \\
0.92\end{array}$ & $\begin{array}{l}6.27 \pm \\
1.01 \\
6.33 \pm \\
1.27\end{array}$ & $\begin{array}{l}5.99 \\
1.03 \\
6.12 \\
1.24\end{array}$ \\
\hline
\end{tabular}

Regional cerebral metabolic rate of glucose CMRGlu (mean \pm SD) expressed in mg glucose/min/100 mg brain in alcoholics and six age-matched contx subjects. Abbreviations for regions as in fig 1 .

collected through a radial arterial catheter. Arterial plasma glucose content was averaged from four samples. The ${ }^{18} \mathrm{FDG}$ cerebral images $\left(2 \times 10^{6}\right.$ counts, each $)$ were scanned 45 to $70 \mathrm{~min}$ after the IV injection of $8 \mathrm{mCi}$ of ${ }^{18} \mathrm{FDG}$. Quantitative CMRGlu images were obtained using the "autoradiographic" method developed by Phelps and coworkers with values of gray matter FDG rate constants $\left(k_{1}\right.$ $\left.=0 \cdot 102, \mathrm{k}_{2}=0 \cdot 13, \mathrm{k}_{3}=0.062, \mathrm{k}_{4}=0.0068\right)$ and a lumped constant ( $\mathrm{LC}=0.42$ ) measured by these authors in healthy volunteers. ${ }^{26}$ In addition, 12 serial scans of the middle brain level were scanned from the end of injection time up to $55 \mathrm{~min}$. This allowed, by means of least-square fitting procedure developed in our laboratory, ${ }^{27}$ a calculation of the individual regional values of the three FDG rate constants: $k_{1}, k_{2}, k_{3}$, ( $k_{4}$ being considered as negligible with this method) and the corresponding, supposedly more reliable, "kinetic" CMRGlu value. The same LC value $(0 \cdot 42)$ was used.

Data analysis In each subject, 30 regional CMRGlu values were obtained from an initial set of 42 standardised $4 \mathrm{~cm}^{2}$ circular regions of interest, pooled together in meaningful anatomical areas (fig 1). In addition, for the two upper brain levels, cortical regional distribution index (RDI) were defined as the ratio of absolute regional value to the corresponding mean cortical value (the mean cortical value being the average value of all symmetrical cortical areas in the corresponding plane). A similar set of data was obtained in a control group consisting of six age-matched subjects $(50 \cdot 2$ \pm 9.9 years), non alcoholic subjects, who were free from overt dementia or cerebro-vascular risk factors. Statistical analysis was performed region by region using two-tailed Student $t$ test.

\section{Results}

Clinical data Four men and two women were selected. Their mean age $( \pm$ SD) was $49 \cdot 8 \pm 8 \cdot 2$ years (range 40-59). Reported duration of alcohol intoxication varied from 5 to 25 years $(13 \pm 8)$ with a usual daily consumption of alcohol ranging from $150 \mathrm{~g}$ to $400 \mathrm{~g}(200 \pm 98 \mathrm{~g})$. Educational levels were low $(<5$ years), median, or high ( $>10$ years) in two, three and one subjects, respectively. Four subjects had poor

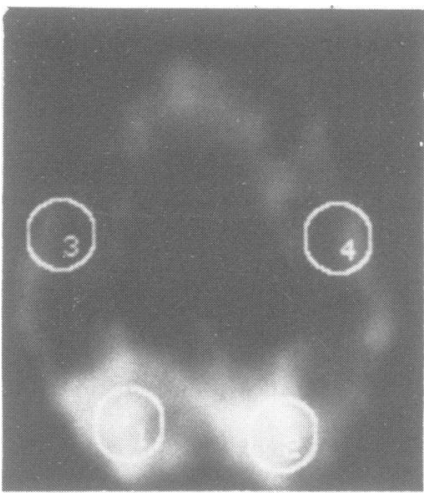

1

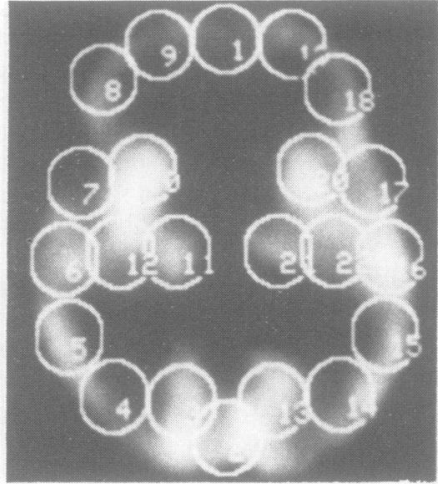

2

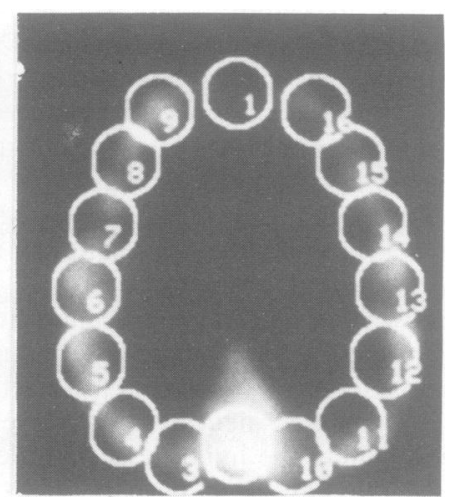

3

Fig 1 Set of circular regions of interest (ROIs) used to define the "anatomical" regions. On Plane 1 (OM + $15 \mathrm{~mm})$ left hand side: Cerebellum $(\mathrm{Cb}): \neq 1 ;$ Temporal area $(\mathrm{TI}): \neq 2 ;$ On Plane 2, (OM $+35 \mathrm{~mm})$ left hand side: Thalamus $(T K) \neq 11$; lenticular nucleus $(L t) \neq 12 ;$ Caudate nucleus $(C d) \neq 10$; latero-frontal area $(L F$ $I I): \neq 8,9 ;$ Temporal area $(T I I): \neq 6,7 ;$ Temporo-occipital area $(T O): \neq 1,5 ;$ occipito-lateral area (LO II): $\neq$ 3; The low medio-frontal (MF II) and medio-occipital (OM II) areas are ROIs $\neq 1$ and 2 respectively; On Plane $3(O M+55 \mathrm{~mm})$ left hand side: latero-frontal area $(L F I I I): \neq 8,9$; sensori-motor area $(S M): \neq 7,6$; parieto-occipital area: $\neq 4,5$; and occipito-lateral area $(O L$ III): $\neq 3$; The upper medio-frontal (MF III) and medio-occipital $(O M I I)$ areas are ROIs $\neq 1$ and $\neq 2$ respectively; Symmetrical ROIs were automatically copied on the right hemisphere. 
Local cerebral glucose utilisation in chronic alcoholics: a positron tomographic study

\begin{tabular}{|c|c|c|c|c|c|c|c|c|c|c|c|c|c|c|c|}
\hline & $R$ & $M F I I I$ & MO III & \multicolumn{2}{|l|}{$L F I I I$} & \multicolumn{2}{|l|}{ S.M. } & \multicolumn{2}{|l|}{ P.O. } & \multicolumn{2}{|l|}{$O L I I I$} & \multicolumn{2}{|l|}{$T I$} & \multicolumn{2}{|l|}{$C b$} \\
\hline $\begin{array}{l}46 \pm \\
38 \pm \\
23 \pm \\
33\end{array}$ & $\begin{array}{l}6 \cdot 40 \pm \\
1.43 \\
6 \cdot 16 \pm \\
0.93\end{array}$ & $\begin{array}{l}5.91 \pm \\
1.05^{*} \\
7.14 \pm \\
1.07\end{array}$ & $\begin{array}{l}8.24 \pm \\
1.51 \\
9.07 \pm \\
0.98\end{array}$ & $\begin{array}{l}6.04 \pm \\
0.95 \\
6.58 \pm \\
0.87\end{array}$ & $\begin{array}{l}5.97 \pm \\
0.93 \pm \\
6.61 \pm \\
0.74\end{array}$ & $\begin{array}{l}6 \cdot 21 \pm \\
1 \cdot 10 \\
7 \cdot 10 \pm \\
1 \cdot 5\end{array}$ & $\begin{array}{l}6.09 \pm \\
1.04 \\
7 \cdot 17 \pm \\
1.24\end{array}$ & $\begin{array}{l}6.34 \pm \\
1.05 \\
6.64 \pm \\
0.91\end{array}$ & $\begin{array}{l}6 \cdot 21 \pm \\
1 \cdot 10 \\
6 \cdot 87 \pm \\
0 \cdot 92\end{array}$ & $\begin{array}{l}7.53 \pm \\
1.24 \\
8.25 \pm \\
0.7\end{array}$ & $\begin{array}{l}7 \cdot 36 \pm \\
1 \cdot 07 \\
8 \cdot 07 \pm \\
0.87\end{array}$ & $\begin{array}{l}4.88 \pm \\
0.99 \\
5.36 \pm \\
0.51\end{array}$ & $\begin{array}{l}5.06 \pm \\
1.08 \\
5.67 \pm \\
0.59\end{array}$ & $\begin{array}{l}6.86 \pm \\
1.07 \\
7.03 \pm \\
1.26\end{array}$ & $\begin{array}{l}6.95 \pm \\
1.11 \pm \\
7 \cdot 16 \pm \\
1.08\end{array}$ \\
\hline
\end{tabular}

$\mathrm{n}$ this region, statistical significance was nearly reached: $(\mathrm{p}=0.07)$.

socioprofessional adjustment. None of the subjects had persistent withdrawal signs at the time of study, although two patients did experience some initially. The sole abnormal neurological finding was asymptomatic polyneuritis in two subjects. No significant anomalies were detected by EEG. At admission gamma-amino-glutamyl transferase levels were markly increased in five subjects and RBC macrocytosis was found in all six subjects; coagulation tests were normal in each case.

The CT scans were analysed according to established criteria modified from Lishman. ${ }^{5}$ Using this scale, widening of cortical sulci was marked, moderate or absent in two, three and one patients, respectively. Mild widening of the interhemispheric fissure was found in two patients. Enlargement of lateral ventricles was moderate in three subjects and questionable in two.
Neuropsychological examination Cognitive and intellectual functions were normal in five subjects and moderately impaired in one. Four subjects had visuoconstructional difficulties. Graphic and gestural Luria tests (studied in five subjects) were impaired in three patients. Memory impairment was detected in four subjects, affecting predominantly visual memory in two subjects. It must be stressed however, that this memory impairment was of a very mild degree compared with, for example, Wernicke-Korsakoff psychosis. $^{28}$

Regional cerebral glucose utilisation Although cortical regional CMRGlu values were slightly lower in alcoholics than in controls, the differences never reached statistical significance (table). However, in the upper medio-frontal region, the CMRGlu was reduced by $17 \%$ in alcoholics just short of statistical significance $(\mathrm{p}=0 \cdot 07)$. In subcortical regions and in

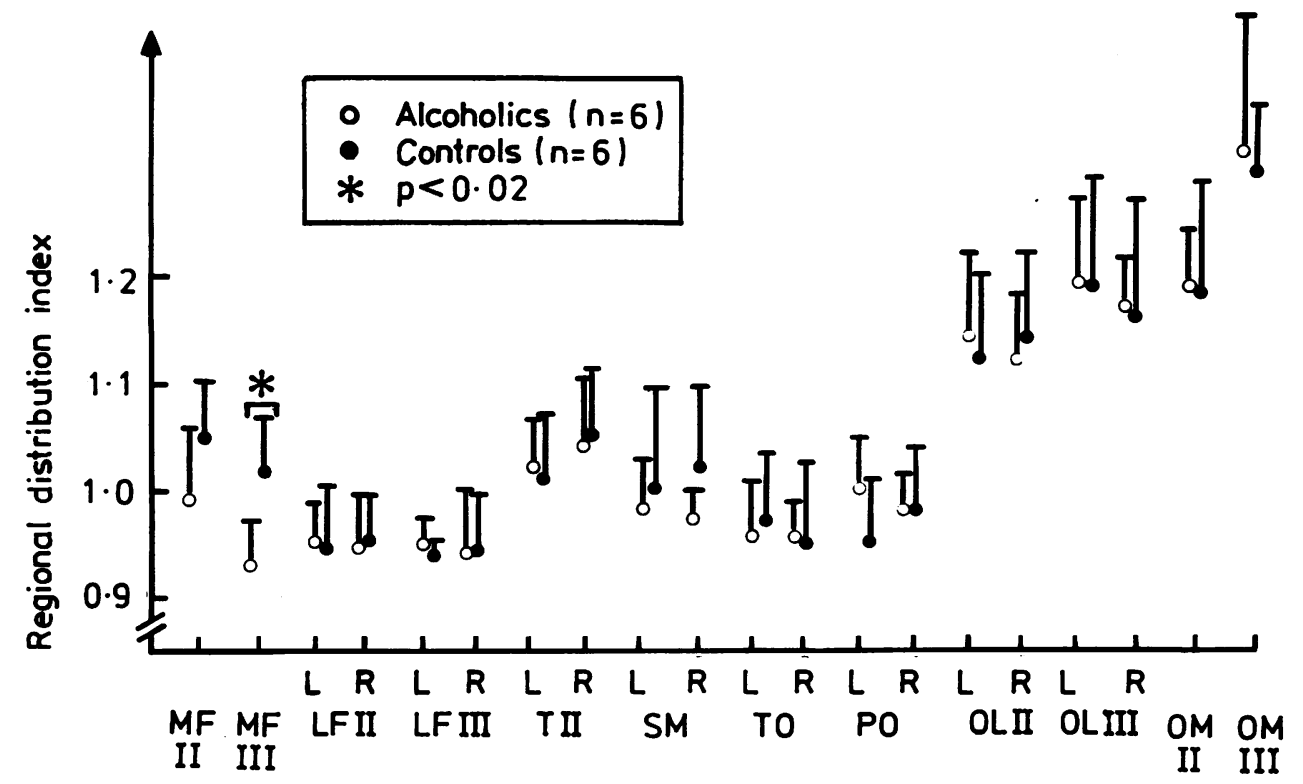

Fig 2 Cortical regional distribution index (mean $\pm S D$ ) in alcoholics and control subjects. Abbreviations for regions as in fig $1 ; L=$ left, $R=$ right. This index is defined as the ratio of the regional metabolic value to the mean cortical value of the corresponding slice (see methods). A selective significant decrease is found in the upper medio-frontal region of the alcoholic group with respect to age-matched controls. 
cerebellum, the CMRGlu values found lay close to control values.

The regional distribution indexes (RDIs) (fig 2) (which reflect accurately the regional metabolic pattern) were decreased in alcoholics in both mediofrontal areas (MF III $=-9 \%, \mathrm{p}<0.02$; MF II $=$ $-6 \%$, NS). The RDIs of the remaining cortical regions were similar in alcoholics and controls, with a mean value $( \pm \mathrm{SD})$ of the differences among groups of $+1.3 \% \pm 1.8 \%$. Hemispheric and regional right to left ratios were not statistically different in alcoholics and controls (data not shown).

\section{Discussion}

In this work, we have studied a small number of highly selected subjects constituting a fairly homogeneous group to detect potential regional cerebral metabolic anomalies during primary chronic alcoholism. A few factors, directly related to the design of this study or to the FDG-PET technique may have interacted with our results. First, both the small number of subjects and the scatter of absolute CMRGlu values result in a low statistical power for the detection of small metabolic anomalies, that is exposing to a betatype of error. However the use of RDIs, which are remarkably stable in normal subjects, ${ }^{29}$ greatly improves the sensitivity of the method in the detection of consistent focal anomalies, because it compensates for the intersubject variability in mean CMRGlu. Second, excluding neurologically and physically impaired subjects, a necessary condition for a valid study, might in turn have selected a "supranormal" population of chronic alcoholics; however neuropsychological and CT scan findings in our patients were similar to those reported in more extensive studies of chronic alcoholics ${ }^{1-511-16}$ indicating that our sample remains representative of long-term alcohol abusers. Third, the validity of the autoradiographic FDG model to quantify CMRGlu may be questioned if chronic exposure to alcohol were to affect the FDG rate and "lumped" constants. However, glucose transport across the blood-brain barrier is unaffected in rats by chronic alcohol intoxication. ${ }^{30}$ Furthermore, using a "kinetic" model (see Methods) to measure the regional rate constants in each of our subjects we found that the mean cortical values of $\mathrm{k}_{1}{ }^{*}, \mathrm{k}_{2}{ }^{*}$, $\mathrm{k}_{3}{ }^{*}$ (respectively $0.094 \pm 0.016,0.115 \pm 0.009,0.037$ \pm 0.006 ) were similar to control values. ${ }^{31}$ Finally, it is recognised that, owing to limited spatial resolution, the anatomical localisation of the ROIs remains only approximate, especially regarding the subcortical structures for which the results presented here should be taken as tentative. In addition, important struc- tures (such as hippocampus) are too small to be analysed accurately using our present detection device and the relatively large size of the ROIs, chosen to improve the statistical precision of the data,${ }^{25}$ may have underestimated real metabolic alterations.

With these potential limitations in mind, we failed to find significant widespread changes in cortical CMRGlu in alcoholics. The trend of decrease found in most cortical areas (table) may reflect a partial volume effect, given the mild cortical atrophy found in five of our six subjects. This almost negative finding indicates that the so called "alcoholic atrophy" is not associated with marked metabolic impairment. This is in line with its potential reversibility, suggesting a shrinkage of the cortical mantle rather than true atrophy. ${ }^{15}$ However, our results contrast with the reported reduction in hemispheric blood flow related to alcohol consumption. ${ }^{6-8}$ This discrepancy probably reflects differences in study design and particularly in subject selection, although uncoupling between flow and metabolism from chronic alcoholism cannot be ruled out. Likewise, we did not find any significant cortical metabolic asymmetry; our data therefore do not support the selective right hemispheric dysfunction suggested previously on the basis of neuropsychological alterations (see Ref 1 for review).

Our results suggest, however, a selective mediofrontal hypometabolism in our patients. The RDI was significantly decreased in the MF III region $(-9 \%, p<0.02)$ with a similar trend in the MF II regions $(-6 \%, \mathrm{NS})$; in addition, they stand out sharply among the remaining regional RDI values which were extremely similar to control values (fig 2). This would support the pathophysiological meaning of those anomalies, namely a consistent alteration of the regional metabolic pattern. However, the changes in $\mathrm{MF}$ areas remained too small to be detected reliably in absolute CMRGlu values which are subject to marked global unspecific variations (table).

To the best of our knowledge this selective functional anomaly has not been reported previously in CBF studies of alcoholics, but this may be due to the inability of standard CBF techniques to monitor the medial surface of the cerebral hemispheres. ${ }^{32}$ This selective medio-frontal hypometabolism cannot be readily explained by interhemispheric cortical atrophy, because the latter was significant in only two of six subjects, remained very mild, and was always associated with a more diffuse cortical atrophy that should not have affected the metabolic pattern; furthermore, exclusion of those two subjects does not alter the statistical significance of the finding. Alternatively our finding may imply selective neuronal loss in medial frontal cortex in alcoholics, but we are not aware of morphometrical studies on human pathological samples to support this hypothesis. In rodents, 
however, chronic exposure to alcohol results in neuronal loss and dendritic changes in hippocampus and cerebellum $^{2223}$ but other cortical areas were not described. Finally, the MF hypometabolism could suggest a neuronal dysfunction without actual cell loss. Anatomically, our MF ROIs essentially included both anterior cingular gyrus and adjacent rostral medial prefrontal areas, two structures that share some thalamic projections, ${ }^{33}$ have close anatomical interconnections, ${ }^{34}$ and underlie common behavioural correlates, ${ }^{35}$ suggesting a functional unity for the whole medial anterior frontal wall. ${ }^{36}$ The fact that chronic alcoholism impairs behaviour and memory would be consistent with predominantly limbic cortical changes. Interestingly, our two patients who showed no memory impairment had higher MF RDI values $(0.97)$ than the remaining four subjects (range $0.85-0.94)$. In his review on neuropsychological deficits in alcoholics Tarter $^{1}$ suggested a dysfunction of fronto-limbic-diencephalic structures, most likely at the orbito-frontal level. Since the anterior cingulate gyrus is viewed as an interface between prefrontal cortex and limbic system, ${ }^{34}$ our metabolic data would fit Tarter's hypothesis.

Alcohol-related alterations in dopaminergic systems ${ }^{19}$ may underlie the MF hypometabolism: dopaminergic innervation is dense in the cingular gyrus $^{37}$ and this region shows selective CMRGlu changes after dopaminergic phamacological interventions in rats. ${ }^{38}$ Alternatively, subtle thiamine deficiency may be considered, since characteristic diencephalic lesions have been reported in neurologically normal alcoholics, ${ }^{9}$ and remote effects of anterior thalamic lesions on cingular gyrus metabolism may be envisioned. Finally these metabolic anomalies may antedate the additive behaviour as may also be true of some of the neuropsychological changes found in alcoholics. ${ }^{39}$

We are deeply indebted to Professor JL Signoret for his support, to Dr M Baulac for helpful discussion and to Mrs $\mathrm{N}$ Benoit for performing the neuropsychological tests.

\section{References}

${ }^{1}$ Tarter RE. Psychological deficit in chronic alcoholics: a reveiw. Int J Addict 1975;10:327-68.

${ }^{2}$ Parsons OA. Neuropsychological deficits in alcoholics facts and fancies. Alcohol Clin Exp Res 1977;1:51-6.

${ }^{3}$ Acker W. Objective psychological changes in alcoholics after the withdrawal of alcohol. Br Med Bull 1982;38:95-8.

${ }^{4}$ Ron MA. Brain damage in chronic alcoholism: a neuropathological, neuroradiological and psychological review. Psychol Med 1977;7:103-12.
${ }^{5}$ Lishman WA. Cerebral disorder in alcoholism syndromes of impairment. Brain 1981;104:1-20.

${ }^{6}$ Berglund M. Cerebral blood flow in chronic alcoholics. Alcohol Clin Exp Res 1981;5:295-303.

${ }^{7}$ Berglund M, Sonesson B. Personality impairment in alcoholism. Its relation to regional cerebral blood flow and psychometric performance. J Stud Alcohol 1976; 37:298-310.

${ }^{8}$ Rogers RL, Meyer JS, Shaw TG, Mortel KF. Reductions in regional cerebral blood flow associated with chronic consumption of alcohol. J Am Geriatr 1983;31:540-3.

${ }^{9}$ Torvik A, Lindboe CF, Rogde S. Brain lesions in alcoholics. J Neurol Sc 1982;56:233-48.

${ }^{10}$ Lynch MJG. Brain lesions in chronic alcoholism. Arch Pathol Lab Med 1960;69:342-53.

${ }^{11}$ Fox JH, Ramsey RG, Huckman MS, Proske AE. Cerebral ventricular enlargement in chronic alcoholics examined by computerized tomography. JAMA 1976;236:365-8.

${ }^{12}$ Graff-Radford NR, Heaton RK, Earnest MP, Rudikoff JL. Brain atrophy and neuropsychological impairment in young alcoholics. $J$ Stud Alcohol 1982;43:859-68.

${ }^{13}$ Ishii T. A comparison of cerebral atrophy in CT scan findings among alcoholic groups. Acta Psychiatr Scand 1983;Suppl 309:7-30.

${ }^{14}$ Ron MA, Acker W, Shaw GK, Lishman WA. Computerized tomography of the brain in chronic alcoholism. A survey and follow-up study. Brain 1982;105:497-514.

${ }^{15}$ Cala LA, Jones B, Burns P, Davis RE, Stenhouse N, Mastaglia FL. Results of computerized tomography, psychometric testing and dietary studies in social drinkers, with emphasis on reversibility after abstinence. Med $J$ Aust 1983;2:264-9.

${ }^{16}$ Carlen PL, Wilkinson DA, Wortzman G, et al. Cerebral atrophy and functional deficits in alcoholics without apparent liver disease. Neurology 1981;31:377-85.

${ }^{17}$ Urbaski SR, Grujic-Injac B, Ristic M. Phospholipid and ganglioside composition in rat brain after chronic intake of ethanol. J Neurochem 1984;42:1235-9.

${ }^{18}$ Melgaard B. The neurotoxicity of ethanol. Acta Neurol Scand 1983;67:131-42.

${ }^{19}$ Reggiani A, Barbaccia ML, Spano PF, Trabucchi M. Dopamine metabolism and receptor function after acute and chronic ethanol. $J$ Neurochem 1979;35:34-7.

${ }^{20}$ Bosio A, Lucchi L, Spano PF, Trabucchi M. Central toxic effects of chronic ethanol treatment: actions on GABA and benzodiazepine recognition sites. Toxicol Lett 1982;13:99-104.

${ }^{21}$ Tran VT, Snyder SH, Major LF, Hawley RJ. Gaba receptors are increased in brains of alcoholics. Ann Neurol 1981;9:289-92.

${ }^{22}$ Walker DW, Barnes DE, Zornetzer SF, Hunter BE, Kubanis P. Neuronal loss in hippocampus induced by prolonged ethanol consumption in rats. Science 1980;209:711-3.

${ }^{23}$ Walker DW, Hunter BE, Abraham WC. Neuroanatomical and functional deficits subsequent to chronic ethanol administration in animals. Alcohol Clin Exp Res 1981;5:267-82.

${ }^{24}$ Loiseau P, Signoret JL, Strube E, Broustet D, Dartigues JF. Nouveaux procédés d'appréciation des troubles de la mémoire chez les épileptiques. Rev Neurol (Paris) 
1982;138:387-400

${ }^{25}$ Lebrun-Grandie P, Baron JC, Soussaline F, Loc'h C, Sastre J, Bousser MG. Coupling between regional blood flow and oxygen utilization in the normal human brain. A study with positron tomography and oxygen 15. Arch Neurol 1983;40:230-6.

${ }^{26}$ Phelps ME, Huang SC, Hoffmann EJ, Selin C, Sokoloff L, Kuhl DE. Tomographic measurement of local cerebral glucose metabolic rate in humans with [F-18] 2-fluoro-2-deoxy-D-glucose: validation of method. Ann Neurol 1979;6:371-88.

${ }^{27}$ Baron JC, Rougemont D, Soussaline F, et al. Local interrelationships of cerebral oxygen consumption and glucose utilization in normal subjects and in ischemic stroke patients: a positron tomography study. J Cereb Blood Flow Metabol 1984;4:140-9.

${ }^{28}$ Victor M, Adams RD, Collins GH. The WernickeKorsakoff Syndrome. Oxford: Blackwell, 1971.

${ }^{29}$ Metter EJ, Riege WH, Kuhl DE, Phelps ME. Cerebral metabolic relationships for selected brain regions in healthy adults. J Cereb Blood Flow Metabol 1984;4:1-7.

${ }^{30}$ Hemmingsen R, Hertz MM, Bolwig TG. Integrity of blood-brain barrier during ethanol intoxication and withdrawal in the rat: normal glucose transfer and permeability to $\mathrm{Na}+$ and $\mathrm{cl}-$. Stroke 1980;11:141-4.

${ }^{31}$ Rougemont D, Baron JC, Collard P, Bustany $P$, Comar D, Agid Y. Local cerebral glucose utilization in treated and untreated patients with parkinson's disease. J Neurol Neurosurg Psychiatry 1984;47:824-30.

${ }^{32}$ Eichling J. Noninvasive methods of measuring regional cerebral blood flow. In: Price TE, Nelson E, eds. Cerebrovascular Diseases. New York: Raven Press, 1979:51-6.

${ }^{33}$ Tobias TJ. Afferents to prefrontal cortex from the thalamic mediodorsal nucleus in the rhesus monkey. Brain Res 1975;83:191-212.

${ }^{34}$ Baleydier C, Mauguiere F. The duality of the cingulate gyrus in monkey. Brain 1980;103:525-54.

${ }^{35}$ Fuster JM. The Prefrontal Cortex. New York: Raven Press, 1980.

${ }^{36}$ Laplane D, Degos JD, Baulic M, Gray F. Bilateral infarction of the anterior cingulate gyri and of the fornices. J Neurol Sc 1981;51:289-300.

${ }^{37}$ Porrino LJ, Goldman-Rakic PS. Brain stem innervation of prefrontal and anterior cingulate cortex in the rhesus monkey revealed by retrograde transport of HRP. $J$ Comp Neurol 1982;205:63-76.

${ }^{38} \mathrm{McC}$ ulloch J. Mapping functional alterations in the CNS with $\left({ }^{14} \mathrm{C}\right)$ deoxyglucose. In: Iversen $\mathrm{S}$, Snyder SH, eds. Handbook of Psychopharmacology. New York: Plenum Press, 1983:321-411.

${ }^{39}$ Tarter RE, Alterman AI. Neuropsychological deficits in alcoholics etiological considerations. J Stud Alcohol 1984;45:1-9. 